\title{
No dogs. Guide dogs by prior permission
}

Esther Rantzen ${ }^{1}$ created the Jobsworth ${ }^{2}$ Award before the National Health Service (NHS) invented clinical governance. One wonders sometimes if the NHS would have scooped all their awards had the programme continued. Television presenters also caution against involvement with children or animals, or worst of all both simultaneously. Clearly child and adolescent mental health professionals planning to involve animals in therapy should be cautious even in a semi-rural locality. Animals and children are, however, within our knowledge and skills framework, but not so the finer points of clinical governance.

In 2000 when the 'No dogs' sign appeared on the door of the community hospital, I felt obliged to seek permission to continue my practice of occasionally using a dog as a co-therapist. By return I received a memo: 'Whose dog? Where does it come from? Where will it go? Who will be responsible? What if fleas get into the carpets?' This seemed to require formal answers so I wrote as follows:

Firstly we do have referred a number of patients with animal phobia who, sooner or later, require desensitisation to real animals such as dogs. Obviously we could only consider bringing a safe, clean, domestic animal into a clinic setting (no lions). The most common type of animal phobia we are asked to deal with is dog phobia, as this often affects children on their way to school and their general social development. We normally draw on a hierarchy of dogs, starting with very small quiet dogs and moving up to large bouncier types. Almost always the dogs belong to members of the child guidance staff, although we have occasionally borrowed a Great Dane from a neighbour for the technique known as flooding.

The second therapeutic use for animals is to act as a facilitator with a child who is very difficult to engage. In my own practice this would normally be a child who has autism and is known to avoid interpersonal relationships if possible. In this case the dog would be my own.

With dog desensitisation it would be normal practice to introduce the dog in the therapy room and probably progress to taking it for a short walk in the neighbourhood. As described above various dogs would be used, but all coming from good backgrounds. In the second situation, my dog will come from my home and will be used in the therapy room I am using and nowhere else. Obviously at all times the therapist concerned will be responsible for both the animal and the safety of the child. We would obviously hope that animals would not shed fleas in NHS property, with the same frequency that children shed head lice on our soft furnishings.

One of the strengths of working in a multi-user health clinic is the opportunity to canvas support from more easy-going colleagues . . . so I did. The manager of the primary care trust was concerned about the Great Dane's bladder control (flooding) but otherwise was encouraging. The greatest assistance came from the general practice (A.B.) down the corridor
Thank you for your letter regarding the presence of animals in the Willowbrook Health Centre, which Anne has circulated to the general practitioners for comments. May I say that I would be delighted to welcome animals into the health centre, the bigger and cuddlier the better. I am sure that our patients would be greatly entertained by the presence of some furry friends as they wait to be seen by the doctor.

Could I perhaps add a couple of provisions:

- With regard to dogs, very loud barky types might cause us problems during the baby clinic.

- Regarding birds, budgerigars and cockatiels would be most welcome but I would be reluctant to have too many parrots around the building because of the medical confidentiality problems that this might cause.

- Regarding scary species, it would be preferable that large spiders, snakes and rats would be kept out of sight of our members of staff because of the high frequency of phobias among them. Larger animals, rhinos and elephants should be well chained to the trees at the rear of the building and out of reach of the car park. Giraffes, however, would not be a problem and would generate a huge amount of interest if they were kept close to the building so that they could be fed from the first floor windows

- Finally, crocodiles and hippos. In view of the unpredictable behaviour of these two species, I suggest they are kept fenced off in the boating lake and only brought into the building when absolutely necessary.

I have probably missed out some important species but I hope these general comments are helpful.

I suppose the conventional approach would have been to write a trust policy document covering all contingencies and responsibilities. More provocative would have been to challenge management using Senge's 'Five Whys' (Senge et al, 1994) technique (using the question 'why' to successively cover/uncover how established practice has come about). As it transpired humour won through to give us the go-ahead for a trial with a review after a year.

\section{Declaration of interest}

Both authors own a number of animals including; dogs, cats, sheep, horse and Shetland pony.

\section{Reference}

SENGE, P. M., ROBERTS, C., ROSS, R. B., et al (1994) The Fifth Discipline

Fieldbook: Strategies and Tools for

Building a Learning Organization. New

York: Doubleday.

*James Pease Consultant Child and Adolescent Psychiatrist, Clarendon House, 8-12 Station Road, Kettering NN15 7HH email: lyn.richardson@northants.nhs.uk, Anthony Brown General Practitioner, Willowbrook Health Centre, Corby, Northamptonshire
1. Presenter of 1970s satirical current affairsTV programme'That's Life.

2.'No, not possible, it's more than my job's worth to be 'flexible'. 